\title{
A Função do Movimento Rotacional nas Teorias dos Pré-Socráticos
}

(The Whirling-Process in Pre-Socratics Cosmogonies)

\author{
José Plínio Baptista \\ Departamento de Física \\ Universidade Federal do Espírito Santo \\ Campus de Goiabeiras, 29060.900, Vitória, ES. \\ e-mail:plinio@cce.ufes.br
}

Recebido em 29 de novembro, 2002. Aceito em 30 de janeiro, 2003

\begin{abstract}
Apresentamos no presente trabalho uma descrição possível do processo responsável pela migração da matéria devido à ação do movimento turbilhonar no interior da substância primordial dos pensadores pré-socráticos. Ressaltamos a dificuldade de se aplicar esta interpretação à teoria cosmogônica de René Descartes. Discutimos brevemente a contestação de Paul Tannery quanto à infinitude do Ápeiron.
\end{abstract}

We give in this work a possible interpretation of the process due to the action of the rotational movement on the primordial substance of the pre-socratics thinkers which results in the separation of its light components from the heavier one. We give also some arguments for the difficulty to extending this interpretation to the cosmogonic theory of René Descartes.

\section{Introdução}

Até René Descartes, o conceito de movimento evoluiu da simples condição aristotélica de relações entre potência e realização de potência ${ }^{1}$, para uma posição de significado fundamental: a de estado da matéria. Ou seja, pensar na matéria é pensá-la em movimento. Porém, muito antes de Aristóteles lançar suas teorias sobre o movimento, este estado já tinha sido definitivamente associado à matéria ou mesmo à entidade geradora da matéria, princípio de todas as coisas. De fato, o movimento foi postulado simultaneamente com a adoção de um princípio, ou de uma substância primordial, indefinida ou definida, infinita ou limitada, porém matriz (arché) de todo o universo. O movimento, postulado com a definição do princípio, já foi concebido como causa eficiente da geração do universo e estruturação do cosmos. Esta é a condição inicial de todas as cosmogonias postuladas pelos filósofos, desde os pré-socráticos, passando por Empédocles, Anaxágoras e até René Descartes. Segundo Paul Tannery, os primeiros pensadores gregos são, pela tradição, considerados como filósofos e suas opiniões são portanto estudadas sobretudo por filósofos, e os historiadores da ciência admitem, sem maiores aprofundamentos, as conclusões formuladas pelos historiadores filósofos. Mas a história filosófica deve ser completada pela história científica, a qual, longe de se apoiar na primeira deve ser estabelecida por método inteiramente oposto. Em outras palavras, deve-se estudar os pré-socráticos, partindo da definição de que suas propostas constituem de fato hipóteses científicas e não princípios filosóficos.

A legitimação atestando a natureza essencialmente filosófica das idéias dos pensadores pré-socráticos é sobejamente manifestada nos escritos, críticas e comentários dos filósofos modernos como Nietsche, Hegel, Heidegger, etc.[2]

Entretanto, os fundamentos dos sistemas destes físicos, como os chamava Aristóteles (ou fisiólogos, na opinião de historiadores da ciência) jamais foram idéias filosóficas, pelo contrário estavam baseadas em conhecimentos empíricos, portanto de naturezas concretas e objetivas. $\mathrm{Na}$ opinião dos historiadores da ciência é nessa fase que se admite ocorrer o nascimento da ciência no mundo ocidental.

Contudo, tomando conhecimento das cosmogonias propostas e procedendo a uma primeira análise, tem-se a impressão de que os conceitos envolvidos na estrutura dos fenômenos tratados nestas teorias são conceitos originários diretamente de uma percepção ingênua da dinâmica da natureza, frutos do senso comum. Entretanto, através de uma análise um pouco mais cuidadosa, é possível constatar que, de fato, estes conceitos derivam de observações criteriosas e objetivas da dinâmica da natureza.

As cosmogonias de Anaximandro e Anaxímenes admitem a matéria primordial em seu estado natural, dotada do movimento perpétuo ${ }^{2}$. Este movimento perpétuo é o responsável pela síntese de toda a matéria que mobilia nosso

\footnotetext{
${ }^{1}$ Definição de movimento, Aristóteles,[1]

${ }^{2}$ Com exceção de Anaxágoras e Empédocles, em cujas teorias o movimento é provocado por outras entidades primordiais.
} 
universo gerada pela sua atuação sobre a substância primordial. De Anaximandro sabemos que o elemento primordial, o princípio de todas as coisas é o Ápeiron, entidade infinita $^{3}$ e indefinida que encerra todas as qualidades e seus contrários e que, pela ação do movimento, esta entidade sofre em seu seio uma separação destes opostos, sendo submetida em seguida a um aglutinamento que leva à formação da matéria. Em Anaxímenes a dinâmica é a mesma, com a diferença de que o princípio já não é mais indeterminado como em Anaximandro, mas determinado e tendo a natureza do Ar (pneuma).

O movimento primordial é um movimento de rotação que se instala na substância princípio. Mais precisamente, é um movimento turbilhonar que tem a propriedade de aglomerar no centro do vórtice os componentes mais pesados e frios, separados da matéria primitiva, e conduzir os mais leves e quentes às regiões periféricas pela ação da aceleração centrífuga. Esta dinâmica favorece a produção dos elementos pesados, sólidos e líquidos, concentrados na região central do vórtice e por expansão dos elementos leves, são gerados os gases, ar inflamado, fogo e éther, ao serem transportados às regiões extremas do turbilhão.

No caso do ar, (pneuma), a concentração no centro do vórtice produz sucessivas condensações do ar, transformando-o finalmente em matéria sólida ou pesada, como a terra e a água. A expansão para as regiões periféricas do turbilhão gera, pela rarefação do pneuma, os elementos celestes: o fogo e o éther, (as estrelas, o Sol e os planetas). A mesma solução dinâmica é adotada por Anaxágoras, Empédocles e também pelos atomistas, com algumas diferenciações conceituais próprias a cada teoria. No caso do sistema proposto por Anaxágoras, a substância primordial é infinita e constituída pelas sementes, (ou spermas), porém o movimento é provocado pela inteligência, ou espírito cósmico. Este espírito, Nous, cria um movimento turbilhonar que vai se multiplicando progressivamente por toda a substância primordial de sementes. A concentração das partes mais pesadas no centro do vórtice e a expansão para a periferia dos elementos mais leves se processam semelhantemente às teorias anteriores.

Já na cosmogonia de Empédocles é a migração do fluido do Amor em direção ao centro da substância formada pelos quatro elementos (Terra, Água, Ar e Fogo) componentes elementares da matéria primordial, que gera um movimento rotacional dando nascimento ao mesmo mecanismo formador dos componentes sólidos, líquidos e gasosos do nosso universo.

\section{O embasamento empírico das teo- rias}

O processo todo de transformações, composições e decomposições dos elementos básicos na dinâmica da cosmogênese é muito complexo, mas já foi exaustivamente analisado e comentado pelos historiadores e filósofos da ciência, a começar pelo próprio Aristóteles. Neste trabalho nós nos interessaremos apenas pela explicação de um estágio deste processo, onde pensamos encontrar razões objetivas adicionais que justificam seu emprego adequado nestas teorias cosmogônicas.

Aristóteles, analisando a natureza do mecanismo gerador provocado pelo movimento turbilhonar e empregado nestas teorias, escreve no seu tratado Os Céus[4]:

“... a forma da causação supõe que todos eles se baseiam da observação dos líquidos e do ar, nos quais os corpos maiores e mais pesados sempre se movem para o centro do turbilhão. Isto é pensado por todos os que tentam gerar os céus por este meio para explicar por que a Terra se situa no centro".

\section{II.1 Um modelo simples}

Vamos examinar um modelo simplificado de escoamento de um sistema de partículas finas, através de um sistema de partículas de granulação maior e que aplicaremos em seguida na interpretação do fenômeno que ocorre no turbilhão da cosmogênese. Isto nos possibilitará compreender as migrações das partes da substância primordial para o centro do turbilhão e para a periferia.

Consideremos uma caixa em forma de paralelepípedo cheia de grãos de dimensões distintas e suponhamos esta caixa repousando sobre uma plataforma horizontal com possibilidade de produzir vibrações de pequenas amplitudes. Fazendo vibrar o conjunto todo (Fig. 1) verifica-se que ao cabo de um certo tempo os grãos se rearranjam espacialmente de forma que os de maiores dimensões se distribuem nos niveis mais elevados enquanto os de menores dimensões se alojarão no fundo da caixa. Este tipo de escoamento é chamado de difusão de um sistema de partículas através de outro. É o fenômeno conhecido como percolação ${ }^{4}$ Neste exemplo notemos que os fatores que facilitam a percolação são o campo de gravidade e as vibrações de pequenas amplitudes impostas ao conjunto.

A teoria da percolação faz apelo ao cálculo da probabilidade de percolação que vai depender de vários parâmetros, em geral associados à geometria das distribuições dos aglomerados que se formam no meio percolante e do conseqüente volume dos interstícios. A percolação é um processo similar ao processo de transporte por difusão. O processo puro de difusão seria representado pelo escoamento de um gás através de outro gás, sendo este último o meio difusor. Na percolação o processo de transporte se realiza em presença de um meio estocástico espalhador. Por exemplo, um meio poroso onde os vazios estão distribuídos ao acaso. No caso da difusão em geral não há uma nítida distinção entre o fluido que se difunde e o meio difusor, como é o caso dos gases citado mais acima, ou o exemplo muito comum apresentado nos textos universitários da gota de tinta que se difunde no interior da água. Já no caso da percolação existe uma nítida distinção entre o fluido percolante e o

\footnotetext{
${ }^{3}$ A infinitude espacial é contestada por P. Tannery [3]

${ }^{4} \mathrm{Um}$ exemplo simples e corriqueiro mas nem por isso menos ilustativo foi lembrado pelo colega, Prof. Armando Takeuchi, a respeito do transporte de grãos por caminhões das lavouras para os silos, ou outra destinação qualquer. O caminhão transportando grãos de vários tamanhos em sua caçamba, ao chegar ao seu destino, apresenta-se com os menores grãos no fundo da caçamba e com os maiores nas camadas superficiais.
} 

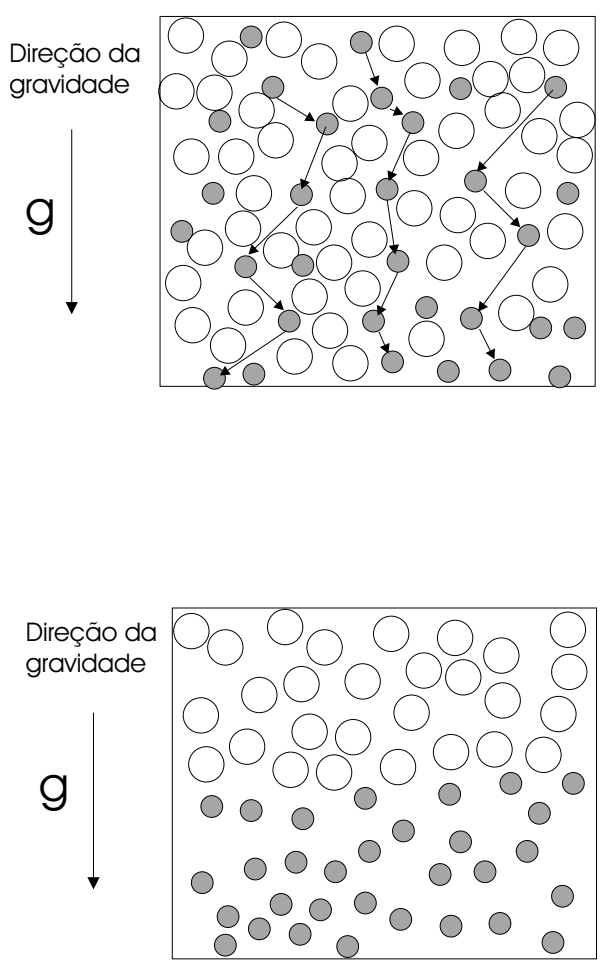

Figura 1. Gráfico de percolação.

meio percolador, que pode ser um meio poroso, apresentando variações ao acaso de ponto para ponto mas, entretanto, constante no tempo. Por outro lado, estes processos similares de transporte se distinguem também por oferecerem limites físicos fundamentalmente diferentes. Um bom exemplo desta diferença é dado no caso da percolação onde um elemento do fluido percolante em sua progressão pelo interior do meio poderá encontrar um sítio vazio, não bloqueado e pelo qual poderá avançar na sua progressão, ou poderá colidir com um sítio represante onde ficará bloqueado. O que não acontece no caso da difusão pura.

A probabilidade de se encontrar um sítio vazio sendo representada por $p$, a probabilidade de se encontrar um sítio bloqueado será dada por $1-p$.

A descrição teórico-matemática do processo de percolação se fundamenta na determinação da probabilidade de percolação em função de $p, f(p)$, que dará a medida da chance de um elemento percolante, partindo de um vazio escolhido ao acaso, atingir infinitos outros vazios. Entre estes caminhos figuram aqueles que através de $n$ passos (ligação entre dois sítios vazios contíguos), "atravessam" o meio poroso. Para se encontrar a probabilidade de percolação para um meio específico, emprega-se em geral o método Monte Carlo, se bem que existam alguns poucos resultados exatos.[8].

\section{II.2 Aplicação aos Turbilhões}

Apesar de inexistir gravidade no interior da matéria primordial, ao se instaurar o movimento de rotação é criado um campo de aceleração centrífuga, que funciona como uma gravidade inercial. Para compreender facilmente o que nos fornece a analogia com o modelo simplificado apresentado mais acima, (parágrafo 2.1), devemos levar em conta o seguinte: no interior do vórtice, e relativo à direção desta gravidade criada, o nivel baixo, "o solo", se localiza na periferia do sistema em rotação e o nivel superior, as partes "altas", se localizam na região central. Para melhor ilustrar a situação imaginemos um ser humano em pé e com os pés na periferia e com a cabeça na direção do centro de rotação.

Vemos então, que por analogia com o exemplo ilustrativo dado, as partes maiores e mais pesadas da matéria primordial que está submetida à ação do vórtice, vão migrar para a região central do vórtice, (para "cima") enquanto as componentes menores e mais leves por percolação são transportadas para a periferia do vórtice (para "baixo") Ver Fig. 2.
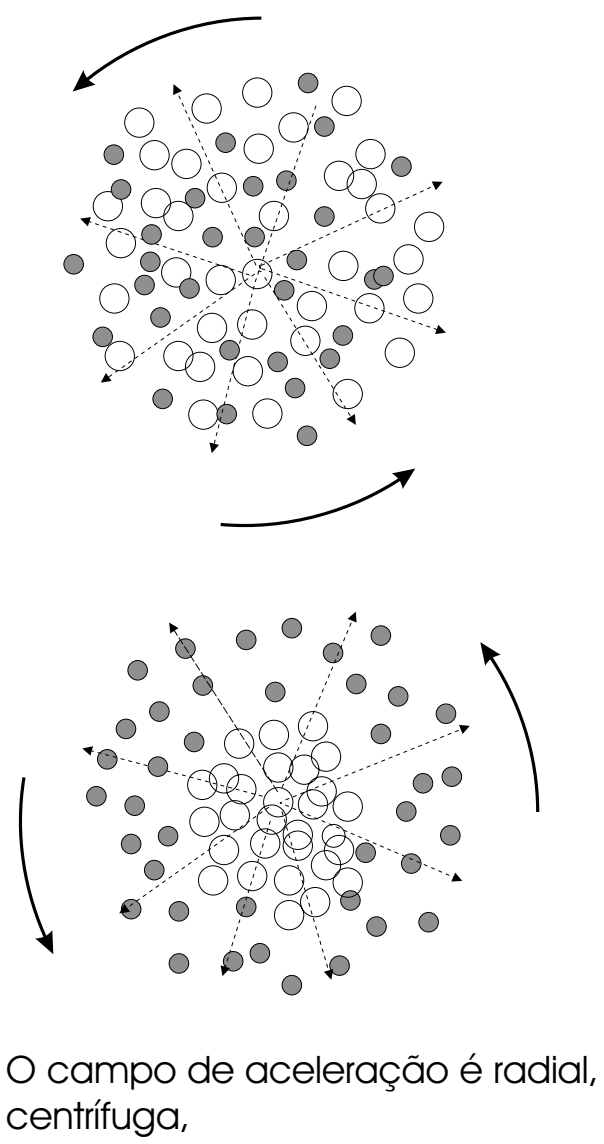

Figura 2. Gráfico de percolação centrífuga.

\section{II.3 A crítica de Paul Tannery}

Muitas questões foram levantadas pelos historiadores sobre os vórtices e suas ações sobre a matéria primordial. Uma questão importante diz respeito à relação da dimensão da extensão espacial da matéria primordial com a suposta ação global do turbilhão.

\footnotetext{
${ }^{5}$ Autores antigos que, pela leitura direta dos escritos originais dos filósofos pré-socráticos, escreveram comentários sobre as teorias propostas. Os seus escritos constituem, modernamente, as únicas fontes de referências.
} 
Paul Tannery[3] contesta a interpretação que dão os doxógrafos ${ }^{5}$ quanto à infinitude do Ápeiron. Sua argumentação se concentra na necessidade imprescindível da compatibilização do movimento turbilhonar com o Ápeiron, uma vez que este movimento é causa eficiente da formação do cosmos. Porém, a extensão espacial infinita da substância primordial é incompatível com o estado de rotação global. Fisicamente, é inadmissível a existência de um vórtice estendendo-se a toda infinitude espacial. A opinião de Tannery é que o Ápeiron de fato não é espacialmente ilimitado, e apresenta um forte argumento justamente na definição da localização da Terra dada por Anaximandro, quando ele afirma que ela permanece no centro e em equilíbrio porque está a igual distância de todas as partes do universo. Ora, como numa extensão espacial infinita não há centro nem borda, deve-se concluir que a afirmação de Anaximandro vale pela afirmação da finitude do Ápeiron!

Para ilustrar a crítica de Tannery consideremos um exemplo simples de movimento turbilhonar que nos fornece a mecânica dos fluidos.

Temos o caso de um líquido incompressível, porém viscoso, girando de tal modo que nas proximidades da origem a velocidade tangencial dos pontos do interior do círculo de raio $r_{0}$ é constante e igual a $v_{0}=v\left(r_{0}\right)$. A distribuição de velocidades para $r>r_{0}$ é dada por,

$$
v(r)=\frac{a}{r}
$$

Como o sistema em movimento não é rígido, o que matematicamente é expresso na função $v(r)$, em regiões suficientemente afastadas do centro do turbilhão a velocidade tangencial se anula. Este turbilhão é adequado à crítica de Tannery quanto à sua extensão espacial, pois vemos facilmente que

$$
r \rightarrow \infty \quad \text { então } \quad v \rightarrow 0
$$

o que significa que o vórtice em questão é limitado. Contudo este exemplo não é inteiramente aplicável às cosmogonias pois este fluido, nesta situação dinâmica, é altamente instável. Porém o comportamento no infinito do campo de velocidades azimutais é sugestivo para o fim de entendermos a crítica de Tannery.

Por outro lado se o fluido, espacialmente finito, tiver uma distribuição de velocidades de forma que a periferia, raio finito, tiver uma velocidade tangencial igual a $v_{R} \neq 0$, a distribuição de velocidades azimutais será 6

$$
v(r)=a r \quad \operatorname{com} \quad a=\Omega,
$$

de modo que a região central se encontra em repouso, pois

$$
v_{0}=\Omega r_{0}, \quad r_{0}=0 \rightarrow v_{0}=0 .
$$

Neste último caso, a região contendo o fluido em movimento turbilhonar é finita e o sistema fluidodinâmico é estável. É claro que se a região do turbilhão se estendesse para o infinito, isto é, $r \rightarrow \infty$ então a definição da velocidade implica que $v \rightarrow \infty$, o que é fisicamente irrealizável. De qualquer modo, esta conclusão não pode ser deduzida no caso acima, pois faz parte das condições iniciais da solução matemática dada, que tenham limites finitos.

Este modelo ilustra o ponto de vista de Paul Tannery sobre a compatibilidade entre a rotação e a finitude do Ápeiron. Além do mais deve ser lembrado, como simples curiosidade, que o sistema "planetário" elaborado por Anaximandro é geocêntrico e no qual os corpos celestes são transportados por anéis que "girariam" com mais rapidez quanto maiores fossem os seus diâmetros. ${ }^{7}$

\section{II.4 A cosmogonia dos atomistas}

$\mathrm{Na}$ filosofia de Leucipo-Demócrito o princípio é representado pela substância primordial constituída de infinitos átomos de infinitas formas e em perpétuo movimento. Nesta teoria, mais que em qualquer outra, a exigência do estado de movimento da matéria primordial, como condição fundamentalmente necessária, é explicitada com argumentação lógica pelos seus criadores. A negação do plenum de Anaxágoras (e posteriormente de Aristóteles) é necessária, é condição sine qua non, para a própria existência dos átomos, pois o estado natural destes é o movimento e o movimento só é possível no vácuo.

Porém como se instaura o movimento rotacional, causa eficiente da geração do universo atomisado? Segundo os criadores da teoria ele surge naturalmente. Os átomos se encontram em movimento livre no vácuo ${ }^{8}$ e encontros e colisões ocorrem por acaso, resultando fatalmente em associações de átomos. No caso em que vários átomos colidem com uma associação incipiente de átomos, em colisão não central, com velocidades dirigidas em sentidos contrários e cujas direções não sejam coincidentes, o movimento turbilhonar se inicia. A substância atômica primordial é de extensão infinita e a situação descrita mais acima se verifica em número incontável de vezes e de lugares. Aparece então uma quantidade infinita de turbilhões, gerando, conseqüentemente, uma infinidade de universos. Os átomos tendo infinitas formas e tamanhos são submetidos, no interior do turbilhão, ao mesmo processo de percolação, possibilitando maior freqüência de colisões na região central, favorecendo a formação de associações de elementos mais pesados formadores de nossa matéria e que mobilia nossos universos. Pela migração para a periferia são geradas as substâncias mais sutis. No aspecto da existência

\footnotetext{
${ }^{6}$ A equação de Navier-Stokes aplicável neste caso tem duas soluções independentes: $v(r)=a r+\frac{b}{r}$

${ }^{7}$ É preciso deixar claro que esta não é uma interpretação da teoria de Anaximandro pois rigorosamente uma interpretação só seria possivel mediante o uso de recursos e conhecimentos compatíveis com a sua época e com seu próprio discurso científico.

${ }^{8}$ Segundo Diógenes Laércio[9], Epicuro dizia que os átomos estão animados de um movimento perpendicular e todos com a mesma velocidade. Para se compreender a geração do universo, segundo esta teoria, deve-se supor que ocorrem desvios destas trajetórias possibilitando colisões entre os átomos. Esta hipótese não coincide com a de Leucipo-Demócrito na qual é admitido que os átomos estão animados de movimento caótico como as partículas de poeira que são vistas a flutuar no ar, quando uma réstia de luz penetra num ambiente escuro.
} 
infinita de mundos, a cosmogonia de Anaxágoras prevê a mesma conseqüência, apresentando porém a dificuldade de se compreender o movimento num plenum onde inexiste o vácuo e imaginado por este filósofo. A substância primordial, os spermas, se estende ao infinito e o Nous provoca o aparecimento de turbilhões em "todas as partes" do infinito gerando assim, semelhantemente à cosmogonia atomística, uma infinidade de mundos. Desta forma, nas cosmogonias de Leucipo-Demócrito e de Anaxágoras o universo é infinito e inumeráveis os mundos que nascem vivem e desaparecem, não necessariamente ao mesmo tempo.

\section{A cosmogonia de René Descartes}

René Descartes considerado o criador da filosofia moderna, foi o autor de inúmeras e importantes contribuições tanto à ciência quanto à filosofia. Um dos seus feitos notáveis foi o enunciado rigoroso do Princípio de Inércia [6]. Meditando sobre a estrutura e fundamento do universo Descartes concluiu que o aspecto essencial da matéria é a sua extensão ${ }^{9}$. Então para Descartes o universo é não-vazio, pois a extensão como uma matéria sutil o preenche completamente. Em função da concepção que Descartes tem sobre o movimento, ele supõe, sem admitir qualquer impossibilidade, o movimento se realizando no pleno. A sua cosmogonia entretanto segue, mutatis mutandi, as mesmas soluções dos pré-socráticos com relação à dinâmica do processo. Descartes igualmente se baseia em dados empíricos para a elaboração de sua teoria cosmogônica. Em uma carta a Mersenne[7] o filósofo descreve:

"para se compreender como a matéria sutil, que gira em torno da Terra, empurra os corpos pesados para o centro, basta encher qualquer vasilha cilíndrica de pequenas esferas de chumbo e colocar entre elas algumas peças de madeira, ou outra matéria mais leve que o chumbo, e que sejam maiores que as esferas de chumbo e depois, fazendo girar fortemente se verá que as pequenas esferas empurrarão todas as peças de madeira, ou outra tal matéria,para o centro da vasilha da mesma forma que a matéria sutil empurra os corpos celestes..."

Seria muito interessante que a mesma interpretação física dada nos parágrafos precedentes pudesse ser aplicada ao caso presente. Porém como veremos, na cosmogonia cartesiana muitas coisas se passam de formas diferentes e originais e que resistem a uma interpretação física fundamentada em dados empíricos como sucede com as teorias dos pré-socráticos. A arché de Descartes é a extensão em movimento e que preenche todo o infinito do universo. Aqui, neste estágio, vai a diferença: a substância básica, a $e x-$ tensão é formada de um mosaico de infinitas regiões, cada uma dotada de um movimento turbilhonar próprio. Neste mosaico de regiões turbilhonares, os vórtices se tocam em suas linhas de fronteiras, e nestas regiões o atrito entre

\footnotetext{
${ }^{9}$ Opção filosófica já adotada por Avicena na idade média.
}

os turbilhões contíguos gera suficiente energia, resultando na criação de toda a matéria de um universo-ilha[5]. Se adotássemos o esquema de interpretação tradicional, imaginaríamos que esta matéria toda seria "derramada dentro do turbilhão" e o processo da percolação deslocaria os corpos para os seus devidos lugares após terminado o processo. Porém a explicação dada por Descartes é um pouco diferente, pois ele afirma que a migração da matéria se faz por meio do processo descrito em sua carta a Mersenne. Ou seja é a matéria sutil que empurra a matéria sólida para o centro do turbilhão. No caso específico da organização do sistema solar, a parte mais pesada migra para o centro do turbilhão se compactando e terminando por formar o Sol. Porém as partes mais leves, planeta, satélites, cometas, etc. são lançadas em direção da periferia. Também empurrada pela matéria sutil? A resposta afirmativa implicaria em atribuir comportamentos contraditórios para esta matéria sutil cartesiana. Então uma vez concluída esta primeira etapa da organização do sistema, os planetas continuariam seus movimentos em órbitas solares, "empurrados" pelo turbilhão centrado no Sol. Esta mecânica celeste foi fortemente contestada pela gravitação universal newtoniana. Newton, em sua obra Princípios Matemáticos de Filosofia Natural declara ter demonstrado que o movimento planetário mantido pelo turbilhão cartesiano não satisfaz às leis de Kepler, portanto esta teoria, não sendo corroborada pela experiência, deve ser abandonada. É fácil de se compreender qual a dificuldade, pois um turbilhão obrigaria um planeta a descrever uma órbita circular contrariando a primeira lei de Kepler. Apesar do seu fracasso em criar uma física, a sua teoria tinha uma preocupação básica interessante. Descartes admitia que as interações entre os corpos só poderiam se realizar por contacto direto. Este aspecto da interação já tinha sido usado na formulação do princípio de inércia, onde as partículas só mudariam suas velocidades pelo contacto com outras.

Esta axiomatização colocava a teoria de Descartes em confronto direto com a teoria de ação à distância de Newton.

Contudo quanto ao resultado final da sua cosmogonia, estamos novamente em presença da criação de infinitos cosmos, semelhantemente às concepções dos atomistas e de Anaxágoras.

\section{Conclusão}

Mostramos nos itens precedentes que as hipóteses cosmogônicas dos físicos pré-socráticos, dos atomistas e de Anaxágoras, tinham um fundamento empírico confirmando sua natureza científica. O que é notável é a originalidade altamente proveitosa destes pensadores, em usar o conhecimento de um fenômeno empírico, terrestre, na interpretação do mecanismo de formação do próprio universo.

Quanto a Descartes, por outro lado, examinando mais atentamente o teor da sua carta transcrita acima, vemos que uma nova função atribuída à ação do vórtice envolve um outro 
processo que foge à interpretação que propusemos nos casos precedentes. Específicamente, esta nova função refere-se à ação da matéria sutil, a extensão, que participa do movimento turbilhonar e empurra a matéria recém criada para o centro do vórtice. Em seguida esta mesma matéria sutil tem a atuação de um agente de contacto com os planetas e que os mantém em suas órbitas, ao mesmo tempo que conserva o Sol em equilíbrio no centro do sistema. Temse a impressão que a intenção do filósofo é afirmar que o movimento de rotação, por si só, tem o dom de deslocar a matéria em direção ao centro do movimento, ou manter o Sol no centro do movimento sem a intervenção de um pocesso físico objetivo, porém provocado pela pressão da matéria sutil. Como já dissemos, este processo não se enquadra na interpretação que propusemos acima, envolvendo o fenômeno da percolação. Além do mais, este processo proposto por Descartes não corresponde exatamente à experiência que ele mesmo sugeriu em sua carta a Mersenne. ${ }^{10}$ Devemos observar finalmente que na referência citada no tratado de Aristóteles $A$ Física e mencionada em parágrafos precedentes, aprendemos que este filósofo tinha por objetivo encontrar razões para explicar por que a Terra se encontra em equilíbrio no centro do mundo. Com este objetivo ele invoca uma explicação provavelmente dada pelo próprio Empédocles:[1]

“... que os céus, se movendo em torno dela a alta velocidade, impede todo movimento da Terra como a água num copo ao qual é dado um movimento circular que mantém esta água no interior do copo...”.
A referência do copo em movimento circular sugere indiscutivelmente a ação de uma força centrífuga. Todavia atribuir à rotação da esfera celeste uma ação centrípeta sobre a Terra de modo a fixá-la no centro de rotação leva à presunção que Aristóteles admitia a existência de algum processo que intermediasse esta ação, o qual igualmente não pode se enquadrar nos casos envolvidos por nossa interpretações dadas neste artigo.

\section{Referências}

[1] Aristóteles, Physics, The Great Books Of The Western World, Enc. Britann. Inc. Chicago, (1989).

[2] Os Pré-Socráticos, coleção Os Pensadores, Editora Abril, São Paulo,(1985).

[3] P. Tannery, Pour L'Histoire de la Science Helène, GauthierVillars, Paris, (1930).

[4] Aristóteles, On the Heavens, book II, Enc. Britann. Inc. Chicago,(1989).

[5] A.C. Crombie, Historia de la Ciencia desde San Agustin a Galileu, Alianza Editorial, Marid, (1959).

[6] J.P. Baptista e L. Ferraccioli, Rev.Bras.Ens.Fis. 22, 272, (2000).

[7] A. Koyré Estudos Galilaicos, Editora Dom Quixote, Lisboa, (1986).

[8] V.K.S Shante e S. Kirkpatrik,An Introduction to Percolation Theory, Advance in Physics, 20, 85, (1971).

[9] D. Laércio, Vie, Doctrines et Sentences des Philosophes Ilustres, Garnier-Flamarion, France, (1965).

\footnotetext{
${ }^{10}$ Devemos lembrar que, na experiência sugerida por Descartes, ele afirma que os corpos mais pesados empurram os mais leves para o centro do movimento.
} 